\title{
Editorial
}

\section{A reflection on the lifestyle of the Czech population}

\author{
Helena Hnilicová * \\ Charles University, First Faculty of Medicine, Institute of Public Health and Medical Law, Prague, Czech Republic
}

The statistics clearly show that the lifestyle of the Czech population is very risky regarding health. Overconsumption of alcohol, smoking and an unhealthy diet is a long-term problem of a large number of the Czech population. Risky behaviour is reflected in the high occurrence of cardiovascular and oncological diseases, which are the most frequent cause of untimely deaths. Scientific findings and practical experience of public healthcare show that people's behaviour is suggestible. Unhealthy habits can be restricted and many chronic diseases can be prevented or postponed to an older age. A number of countries have reached remarkable achievements and recorded a significant decrease in mortality due to cardiovascular diseases - which is no longer the most frequent cause of death. These countries include France, Spain, Portugal, Slovenia, Great Britain, Ireland, Sweden and Norway, which was the last country so far to achieve it in 2013.

From the mentioned behavioural risks, it is mainly the overconsumption of alcohol that creates a negative profile of the Czech Republic. The danger of such overconsumption is especially due to the general acceptance of alcohol as necessary for entertainment and relaxation. Almost no social event in the Czech Republic happens without alcohol. This corresponds with the finding that young people do not drink alcohol too frequently but they drink it in larger quantities, whereas middle-aged and older people consume less alcohol but almost every day. To compare the $C$ zech Republic to the rest of Europe: in 2016, one European older than 15 drank an average of 9.8 litres of pure alcohol whereas one Czech at the same age drank 14.4 litres. Uncomplimentary alcohol statistics are related to the fact that Czech society is very tolerant of alcohol. Unlike many other countries, the presence of children is not an obstacle to drinking. Czech children and adolescents grow up in a strongly pro-alcohol environment and we cannot be surprised by the fact that they also belong to the group of above-average alcohol consumers when compared to their peers from other countries. It is also proven that people who drink probably smoke; and so support the harmful effects of both habits. If such people also have an unhealthy diet, the probability of getting ischemic heart disease, diabetes, a stroke or oncological disease is increased. It is not a coincidence that Czechs are in the first place in the world regarding the incidence and mortality of pancreatic tumour.

I presume that it is time to think about the causes of such a condition and the ways of starting a change. We realize the multifactorial nature that affects human behaviour, so we can assume that health politics has contributed to such a condition because it omitted and underestimated the importance of prevention and health support. From the 1920's up to recent times, academic and political attention has been paid to the system of treatment of patients. The good news is that the Czech Republic is the best-assessed health system regarding the performance and efficiency of the Visegrad Group. However, health is not a product of hospitals or specialized centres of sophisticated medicine. Health is created and strengthened in daily life. It is most desirable that this fact is realized by the Czech experts from public healthcare as well as all medical workers, population and mainly politicians, who could include health support in the priorities of their political agendas and make it part of the strategy for improving the quality of life.

The first steps have already been made. The Ministry of Health of the Czech Republic intends to develop programmes regarding increasing health literacy and restricting the availability of alcohol and cigarettes to create an environment where it is easier to make decisions against smoking and overconsumption of alcohol. The preferred strategies for achieving changes in health behaviour are educational campaigns that are focused on increasing awareness regarding health. The contemporary scientific findings show that sufficient information and good health literacy influence human behaviour less than it was previously assumed. This finding is also supported by the fact that there are many medical workers who smoke despite having sufficient scientifically verified information about its bad effect.

\footnotetext{
* Author for correspondence: Helena Hnilicová, Charles University, First Faculty of Medicine, Institute of Public Health and Medical Law, Prague, Czech Republic; e-mail: hhnil@lf1.cuni.cz http://doi.org/10.32725/kont.2019.031
} 